\title{
AKSES, FUNGSI, DAN POLA PENGGUNAAN TEKNOLOGI INFORMASI DAN KOMUNIKASI (TIK) OLEH PETANI PADA KAWASAN PERTANIAN KOMERSIAL DI KABUPATEN BANTUL
}

\section{ACCESS, FUNCTIONS, AND USE PATTERN OF INFORMATION AND COMMUNICATION TECHNOLOGY (ICT) IN COMMERCIAL AREA IN BANTUL REGENCY}

\author{
Ade Intan Christian ${ }^{1} \&$ Subejo $^{2}$ \\ ${ }^{1}$ Mahasiswa, Penyuluhan dan Komunikasi Pembangunan, Sekolah Pasca Sarjana UGM \\ ${ }^{2}$ Dosen, Penyuluhan dan Komunikasi Pertanian UGM \\ email: adeintanch@yahoo.com
}

\begin{abstract}
Information and Communication Technologies (ICTS) has been considered play an important role for supporting the need of new information and innovation for farmers. Extension and communication based ICTs in developing countries can be used for wider scope of activities including information related to various farming operations. This research discusses a new trend of emergence of ICTs in Bantul Regency for supporting daily life activities of farmer including agricultural activities. Research method of study was descriptive method. In general, farmers have been using television and radio with function for getting information, entertaining, and education. However, hand phone and smart phone to some extent have emerged as additional and important alternative media for farmer. The use of internet via smartphone has newly started to be utilized among farmer in Bantul Regency. Information on agriculture which accessed by farmers was still dominated by production aspect and marketing.
\end{abstract}

Keywords: commercial crops, farmer, media, ICTs

\section{PENDAHULUAN}

Keberlangsungan pertanian, tidak hanya ketersediaan inovasi dan teknologi, namun juga sangat ditentukan oleh keberhasilan sistem penyebarluasan informasi dan inovasi pertanian (information delivery system). Penyebarluasan informasi dan inovasi pertanian telah dilakukan dengan berbagai pendekatan dan mekanisme mulai dari cara konvensional sampai dengan perkembangan yang relatif baru berupa pemanfaatan media masa (media elektronik dan cetak). Dalam perkembangan terkini penyuluhan dan komuniaksi pertanian dengan pemanfaatan new media seperti melalui online system dan jaringan internet dalam bidang pertanian mulai diterapkan di berbagai negara (termasuk negaranegara berkembang).

Elian et al., (2014) menyatakan kemajuan TIK berpotensi menjadi peluang yang besar bagi pelaku pembangunan pertanian. Pemanfaatan teknologi komunikasi dalam pembangunan pertanian memerlukan kompetensi dari pengguna teknologi informasi dan komunikasi tersebut. Petani merupakan salah satu pihak yang lemah akses terhadap sumber informasi sehingga hanya dapat mengandalkan kapasitas penyuluh untuk mendampinginya mengembangkan proses belajar inovasi pertanian

Pendekatan dan praktek penyuluhan pertanian mengalami perubahan yang dinamis. Perubahan pendekatan dan paradigma penyuluhan pertanian sebagaimana dicatat oleh Subejo (2011), digambarkan dalam satudua dekade terakhir terdapat suatu perubahan paradigma dalam penyelenggaraan penyuluhan pertanian di negara-negara berkembang (termasuk di Indonesia) yang disebabkan oleh berbagai perubahan dan tuntutan global. Kecepatan dan ketepatan penyampaian informasi teknologi dan alternatif serta berbagai solusi efektif sangat perlu diperhatikan. Sejak satu-dua dekade terakhir di banyak negara maju bahkan juga negara berkembang mulai 
menaruh perhatian yang besar bagi pemanfaatan Information and Communication Technologies (ICTs) untuk penyelenggaraan penyuluhan pertanian dan pedesaan, atau biasa dikenal di Indonesia dengan istilah Teknologi Informasi dan Komunikasi (TIK).

Jenis dan kemampuan media massa yang terus berkembang dapat melengkapi, bahkan dalam batas tertentu telah menggantikan peran lembaga penyuluhan pertanian konvensional yang selama ini dijalankan oleh petugas penyuluh lapangan di Indonesia. Pemanfaatan media masa dimulai dari model komunikasi satu arah (oneway communication model), yaitu penyebaran informasi secara linier yang memuat inovasiinovasi di bidang pertanian kepada khalayak ramai. Penerima informasi tersebut tidak hanya terbatas untuk petani di wilayah dan komoditas tertentu, namun juga dapat menjangkau seluruh bidang dan komoditas.

Seiring dengan kemajuan teknologi, komunikasi satu arah pada media massa mengalamiperubahanmenjadikomunikasitimbal balik (two-way or interactive communication model) atau dikenal dengan komunikasi interaktif atau komunikasi konvergensi. Model komunikasi ini dilakukan dengan memanfaatkan berbagai media seperti penggunaan telepon, facsimile, SMS (Short Message Service), dan internet (interactive website communication, interactive teleconference, social networking, dan lain-lain).

Ada beberapa kelebihan dan keunggulan media masa elektronik yaitu dalam hal kecepatan informasi, keragaman informasi, jangkauan yang lebih luas, dan biaya yang relatif lebih rendah dibandingkan dengan kunjungan fisik petugas penyuluh lapangan dari lembaga penyuluhan pertanian. Teknologi informasi dan komunikasi (TIK) dapat menjadi sebuah alternatif dalam memperoleh informasi terkait dengan inovasiinovasi pertanian, terutama bagi petani yang mengembangkan komoditas komersial (cash crop). Kebutuhan akan berbagai informasi tentang segala bentuk inovasi yang mendukung kualitas lahan dan peningkatan produktivitas serta berbagai produk pertanian dapat diakses dengan mudah melalui berbagai media, seperti media cetak, televisi, radio, telepon hingga internet.

Teknologi Informasi dan Komunikasi (TIK) sudah merambah ke perdesaan dan menyentuh berbagai aspek kehidupan, bahkan sudah mulai dimanfaatkan untuk mendukung aktivitas pertanian. Hasil studi pendahuluan oleh Subejo et al (2016) tentang pemanfaatan teknologi informasi dan komunikasi di kalangan petani telah menemukan pada kawasan pertanian komersial hortikultura (cabai) di Kabupaten Kulon Progo, media TV dan radio masih dominan digunakan oleh petani, serta handphone dan smartphone/internet sudah mulai digunakan untuk mengakses informasi pertanian. Beberapa penelitian terdahulu yag membahas pemanfaat teknologi informasi pada usaha pertanian antara lain dilakukan oleh Harmoko dan Darmansyah (2016), Bulu dkk (2009), Abidin dkk (2015), Perbedaan penelitian ini dengan penelitian sebelumnya adalah penelitian ini fokus lebih pada pola penggunaan ICTs utuk kebutuhan pertanian (usahatani dan pemasaran).

Berdasar hasil kajian sebelumnya, kajian lanjutan terkait kawasan pertanian komersial nampaknya perlu dikaji lebih mendalam. Oleh karena itu, akses, fungsi, dan pola penggunaan Teknologi Informasi dan Komunikasi (TIK) pada kawasan pertanian komersial tanaman hortikultura sangat menarik untuk diteliti lebih lanjut.

\section{METODE PENELITIAN}

Metode dasar yang digunakan dalam penelitian ini adalah metode deskriptif analitik. Metode deskriptif analitik menurut Nasir (1999) merupakan penggabungan metode deskriptif dan metode analitik yang bertujuan tidak hanya untuk mengetahui kronologi dan gambaran tentang suatu program atau kegiatan, namun juga dapat digunakan untuk mengetahui hubungan antarfaktor yang diteliti untuk mencari berbagai permasalahan yang terjadi di lapangan serta untuk mengetahui bagaimana menentukan cara terbaik untuk menyelesaikannya.

Penelitian akan dilaksanakan di kawasan pertanian komersial yaitu Kabupaten Bantul, Daerah Istimewa Yogyakarta. Sampel kecamatan dipilih secara purposive dengan pertimbangan bahwa Kecamatan Sanden tersebut adalah kawasan pertanian untuk komoditas cabai merah dan bawang merah. Komoditas ini merupakan komoditas komersial. Populasi dalam penelitian ini adalah petani cabai merah dan bawang merah di Kabupaten Bantul. Berdasarkan populasi tersebut, diambil sampel sebanyak 30 petani di Desa Gedangsari, Kecamatan Sanden. Sampel diambil dengan teknik simple random sampling. 
Data yang dikumpulkan dalam pengkajian ini adalah data primer dan data sekunder, di mana data-data tersebut dikumpulkan dengan dua teknik yaitu observasi dan wawancara.

Analisis statistik deskriptif dan deskriptif kualitatif digunakan untuk mengetahui akses, fungsi, dan pola penggunaan TIK bagi masyarakat di kawasan pertanian komersial di Kabupaten Bantul. Statistik deskriptif menurut Mulyadi (2012) dilakukan dengan penjabaran melalui tabel frekuensi, ranking maupun tabel proporsi. Pola penggunaan ICTs dijelaskan untuk kepentingan produksi usahatani, pemasaran, kebijakan, motivasi (cerita sukses), kepentingan kemanusiaan, dan pembiayaan. Desktriptif kualitatif dilakukan melalui langkah-langkah 1) menelaah data yang telah didapatkan dari berbagai sumber; 2) reduksi data yang berupa proses pemilihan, pemusatan, penyederhanaan, pengabstrakan, dan transformasi data; dan 3) kategorisasi yaitu kegiatan penyusunan kategori. (2) Untuk mengetahui faktor-faktor yang mempengaruhi penggunaan TIK untuk pertanian oleh masyarakat di kawasan pertanian komersial di Kabupaten Bantul.

\section{HASIL DAN PEMBAHASAN}

\section{A. Akses Dan Fungsi Tik Dalam Memenuhi Kebutuhan Informasi, Edukasi Dan Entertain}

Petani di Kabupaten Bantul mayoritas sudah memiliki media seperti televisi, radio, handphone, smartphone, laptop, dan VCD/ DVD. Media tersebut digunakan petani sebagai sarana memperoleh informasi, edukasi, dan hiburan. Selanjutnya akan dibahas secara detail terkait kepemilikan TIK dan fungsi TIK secara umum di Kabupaten Bantul.

Petani di Kabupaten Bantul rata-rata memiliki media elektronik antara $100 \%$ ke atas. Media yang paling banyak dimiliki adalah smartphone dengan jumlah sebesar $135,7 \%$ dengan rerata lama penggunaan 1,8 tahun. Hal ini menunjukkan bahwa predikat era digital yang dewasa ini sering digaungkan ternyata juga berlaku bagi para petani tak terkecuali petani di daerah Bantul. Petani yang secara status pendidikan, sosial, maupun ekonomi dipandang lemah jika dibandingkan dengan masyarakatmasyarakat dengan pekerjaan di luar pertanian juga memiliki kemampuan untuk mengikuti perkembangan teknologi informasi.
Tabel 1. Kepemilikan TIK oleh Rumah Tangga Petani di Kabupaten Bantul

\begin{tabular}{lrr}
\hline Media & $\begin{array}{c}\text { Televisi } \\
\text { Jumlah } \\
(\%)\end{array}$ & $\begin{array}{c}\text { Rerata Lama } \\
\text { Kepemilikan } \\
\text { (tahun) }\end{array}$ \\
\hline Televisi & 100 & 14,5 \\
Radio & 100 & 12,8 \\
Handphone & 111,1 & 5,5 \\
Smartphone & 135,7 & 1,8 \\
Laptop & 114,3 & 1,7 \\
VCD/DVD & 100 & 2,9 \\
\hline Sumber:Data Primer diolah $(2017)$ &
\end{tabular}

Sumber: Data Primer diolah (2017)

Berdasarkan Tabel 1 maka diketahui bahwa penggunaan telepon kini telah menjadi sesuatu yang umum di tengah masyarakat, termasuk di kalangan petani. Hal tersebut menunjukkan bahwa pada dasarnya telepon baik itu handphone maupun smartphone merupakan media komunikasi yang potensial untuk digunakan sebagai sumber informasi pertanian.

Fungsi media teknologi informasi dan komunikasi secara umum bagi petani digunakan untuk memenuhi kebutuhan informasi, edukasi, dan untuk sarana hiburan (entertainment). Pada bagian berikut disajikan fungsi TIK di Kabupaten Bantul.

Tabel 2. Fungsi TIK dalam Pemenuhan Informasi, Edukasi dan Entertain di Kabupaten Bantul

\begin{tabular}{|c|c|c|c|c|c|c|}
\hline Jenis TIK & Fungsi Umum & $\mathrm{TP}$ & $\mathrm{J}$ & $\mathrm{KK}$ & $\mathrm{S}$ & $\mathrm{SS}$ \\
\hline \multirow{3}{*}{$\begin{array}{l}\text { Televisi } \\
(n=29)\end{array}$} & Informasi & 3 & 14 & 17 & 38 & 28 \\
\hline & Edukasi & 17 & 24 & 31 & 24 & 3,4 \\
\hline & Entertainment & 3,4 & 21 & 24 & 31 & 24 \\
\hline \multirow{3}{*}{$\begin{array}{l}\text { Radio } \\
(n=20)\end{array}$} & Informasi & 15 & 20 & 30 & 20 & 25 \\
\hline & Edukasi & 25 & 20 & 30 & 25 & 5 \\
\hline & Entertainment & 15 & 15 & 5 & 55 & 20 \\
\hline \multirow{3}{*}{$\begin{array}{l}\text { Handphone } \\
(\mathrm{n}=18)\end{array}$} & Informasi & 17 & 28 & 5,6 & 22 & 39 \\
\hline & Edukasi & 56 & 11 & 11 & 17 & 11 \\
\hline & Entertainment & 50 & 11 & 5,6 & 22 & 11 \\
\hline \multirow{3}{*}{$\begin{array}{l}\text { Smartphone } \\
(n=14)\end{array}$} & Informasi & 29 & 0 & 14 & 36 & 14 \\
\hline & Edukasi & 43 & 21 & 0 & 29 & 0 \\
\hline & Entertainment & 29 & 14 & 7 & 36 & 7,1 \\
\hline \multirow{3}{*}{$\begin{array}{l}\text { Laptop } \\
(n=7)\end{array}$} & Informasi & 57 & 0 & 14 & 14 & 0 \\
\hline & Edukasi & 57 & 14 & 14 & 0 & 0 \\
\hline & Entertainment & 57 & 14 & 14 & 0 & 0 \\
\hline \multirow{3}{*}{$\begin{array}{l}\text { VCD } \\
(n=7)\end{array}$} & Informasi & 86 & 14 & 0 & 0 & 0 \\
\hline & Edukasi & 86 & 14 & 0 & 0 & 0 \\
\hline & Entertainment & 57 & 14 & 29 & 0 & 14 \\
\hline
\end{tabular}

Sumber: Analisis Data Primer, 2017 
Hasil kajian di Kabupaten Bantul menunjukkan media televisi dengan intensitas sangat sering digunakan mayoritas untuk mencari informasi, yaitu sebesar $28 \%$, diikuti $24 \%$ digunakan untuk media hiburan, dan hanya sedikit sekali digunakan untuk edukasi, yaitu 3,4\%. Dalam penggunaannya dari skala intensitas jarang hingga sangat sering, tidak ada yang bernilai $0 \%$. Hal ini karena televisi merupakan media TIK yang sangat umum di kalangan masyarakat termasuk petani sehingga kecenderungan penggunaannya pun besar, baik sebagai sumber informasi, edukasi, maupun sarana hiburan (entertainment).

Media berikutnya adalah radio, media yang sangat sering digunakan untuk mencari informasi sebesar 25\%, sebesar 5\% untuk edukasi, dan sebesar $20 \%$ untuk hiburan. Hal ini menunjukkan bahwasannya radio masih menjadi salah satu media yang digemari masyarakat petani meskipun tidak dalam jumlah yang besar.

Penggunaan handphone oleh petani di Bantul ternyata masih berada pada skala intensitas tidak pernah. Sebanyak $17 \%$ tidak pernah menggunakan handphone untuk mencari informasi, 56\% tidak pernah digunakan untuk edukasi, dan $50 \%$ tidak pernah digunakan untuk kepentingan hiburan. Berbeda dengan smartphone, dimana penggunaan smartphone dalam level sering digunakan mencapai angka yang cukup tinggi. Sebesar 36\% sering digunakan untuk mengakses informasi, 29\% untuk kepentingan edukasi, dan 36\% digunakan untuk sarana hiburan. Hal ini berbanding lurus dengan jumlah kepemilikan media yang ada di lingkup petani Bantul. Disana, mayoritas petani paling banyak memiliki smartphone, sehingga wajar apabila penggunaannya pada skala intensitas sering adalah tinggi baik untuk kepentingan pencarian informasi, edukasi, maupun entertainment.

Mayoritas petani di Kabupaten memiliki kecenderungan tidak pernah menggunakan laptop untuk kepentingan apapun, bahkan 0\% yang menggunakan dengan intensitas sangat sering. Padahal jika dilihat jumlah kepemilikan laptop petani di Bantul adalah sebesar 114,3\%. Namun hal ini bisa saja terjadi, kepemilikan tinggi namun penggunaannya rendah. Ini bisa disebabkan karena petani sebagai kepala keluarga yang membeli laptop namun yang memanfaatkan laptop tersebut adalah istri atau anaknya, namun biasanya lebih cenderung
Tabel 3. Fungsi TIK di Bidang Pertanian di Kabupaten Bantul

\begin{tabular}{|c|c|c|c|c|c|c|}
\hline Jenis TIK & Fungsi TIK & $\begin{array}{l}\text { TP } \\
(\%)\end{array}$ & $\begin{array}{c}J \\
(\%)\end{array}$ & $\begin{array}{l}\text { KK } \\
(\%)\end{array}$ & $\begin{array}{c}\mathrm{S} \\
(\%)\end{array}$ & $\begin{array}{l}\text { SS } \\
(\%)\end{array}$ \\
\hline \multirow{6}{*}{$\begin{array}{c}\text { Televisi } \\
(\mathrm{n}=29)\end{array}$} & $\begin{array}{l}\text { Teknis } \\
\text { Produksi }\end{array}$ & 10 & 24 & 34 & 28 & 3 \\
\hline & Pemasaran & 14 & 31 & 17 & 31 & 7 \\
\hline & Kebijakan & 24 & 24 & 21 & 24 & 7 \\
\hline & $\begin{array}{l}\text { Cerita } \\
\text { Sukses }\end{array}$ & 14 & 28 & 31 & 28 & 0 \\
\hline & $\begin{array}{l}\text { Human } \\
\text { Interest }\end{array}$ & 24 & 24 & 34 & 17 & 0 \\
\hline & Pembiayaan & 38 & 31 & 17 & 14 & 0 \\
\hline \multirow{6}{*}{$\begin{array}{l}\text { Radio } \\
(\mathrm{n}=22)\end{array}$} & $\begin{array}{l}\text { Teknis } \\
\text { Produksi }\end{array}$ & 27 & 27 & 9 & 32 & 5 \\
\hline & Pemasaran & 27 & 36 & 5 & 27 & 5 \\
\hline & Kebijakan & 45 & 27 & 9 & 14 & 5 \\
\hline & $\begin{array}{l}\text { Cerita } \\
\text { Sukses }\end{array}$ & 45 & 36 & 14 & 0 & 5 \\
\hline & $\begin{array}{l}\text { Human } \\
\text { Interest }\end{array}$ & 36 & 45 & 18 & 0 & 0 \\
\hline & Pembiayaan & 45 & 41 & 5 & 9 & 0 \\
\hline \multirow{6}{*}{$\begin{array}{l}\text { Handphone } \\
\qquad(\mathrm{n}=18)\end{array}$} & $\begin{array}{l}\text { Teknis } \\
\text { Produksi }\end{array}$ & 33 & 6 & 11 & 33 & 17 \\
\hline & Pemasaran & 22 & 22 & 11 & 22 & 22 \\
\hline & Kebijakan & 39 & 22 & 11 & 22 & 6 \\
\hline & $\begin{array}{l}\text { Cerita } \\
\text { sukses }\end{array}$ & 44 & 17 & 17 & 22 & 0 \\
\hline & $\begin{array}{l}\text { Human } \\
\text { Interest }\end{array}$ & 44 & 17 & 22 & 17 & 0 \\
\hline & Pembiayaan & 44 & 17 & 6 & 22 & 11 \\
\hline \multirow{6}{*}{$\begin{array}{l}\text { Smartphone } \\
\quad(\mathrm{n}=12)\end{array}$} & $\begin{array}{l}\text { Teknis } \\
\text { Produksi }\end{array}$ & 33 & 17 & 8 & 42 & 0 \\
\hline & Pemasaran & 25 & 17 & 8 & 50 & 0 \\
\hline & Kebijakan & 42 & 25 & 8 & 25 & 0 \\
\hline & Cerita Sukses & 42 & 25 & 8 & 25 & 0 \\
\hline & $\begin{array}{l}\text { Human } \\
\text { Interest }\end{array}$ & 33 & 25 & 17 & 25 & 0 \\
\hline & Pembiayaan & 42 & 33 & 8 & 17 & 0 \\
\hline \multirow{6}{*}{$\begin{array}{c}\text { Laptop/PC } \\
\quad(\mathrm{n}=6)\end{array}$} & $\begin{array}{l}\text { Teknis } \\
\text { Produksi }\end{array}$ & 67 & 0 & 17 & 17 & 0 \\
\hline & Pemasaran & 67 & 0 & 17 & 17 & 0 \\
\hline & Kebijakan & 67 & 0 & 17 & 17 & 0 \\
\hline & Cerita Sukses & 67 & 0 & 17 & 17 & 0 \\
\hline & $\begin{array}{l}\text { Human } \\
\text { Interest }\end{array}$ & 67 & 0 & 17 & 17 & 0 \\
\hline & Pembiayaan & 83 & 0 & 0 & 17 & 0 \\
\hline \multirow{6}{*}{$\begin{array}{l}\text { DVD } \\
(\mathrm{n}=11)\end{array}$} & $\begin{array}{l}\text { Teknis } \\
\text { Produksi }\end{array}$ & 100 & 0 & 0 & 0 & 0 \\
\hline & Pemasaran & 100 & 0 & 0 & 0 & 0 \\
\hline & Kebijakan & 100 & 0 & 0 & 0 & 0 \\
\hline & Cerita Sukses & 100 & 0 & 0 & 0 & 0 \\
\hline & $\begin{array}{l}\text { Human } \\
\text { Interest }\end{array}$ & 100 & 0 & 0 & 0 & 0 \\
\hline & Pembiayaan & 100 & 0 & 0 & 0 & 0 \\
\hline
\end{tabular}

Sumber: Analisis Data Primer, 2017 
anak yang memanfaatkan untuk kepentingan pendidikan atau sekolah mereka. Sementara itu, mayoritas petani masih belum terampil untuk menggunakan laptop karena kerumitan penggunaannya.

VCD/DVD, media yang kebanyakan diperuntukkan dalam rangka kepentingan hiburan, ternyata tidak banyak petani Bantul yang memanfaatkannya. Hanya $14 \%$ petani yang menggunakan pada intensitas sangat sering, sementara $57 \%$ dari mereka tidak pernah memanfaatkan media ini sebagai sarana hiburan. Hal ini bisa saja terjadi karena saat ini media hiburan sudah sangat beragam, dan VCD/DVD bukan lagi menjadi media yang digemari oleh mayoritas petani khususnya di daerah Bantul.

\section{B. Pola Penggunaan TIK Di Bidang Pertanian}

Pemanfaatan media elektronik dalam bidang pertanian menunjukkan secara keseluruhan dari total enam media yang ada, hanya empat media yang mampu menyediakan informasi di bidang pertanian. Media tersebut yaitu (1) televisi, (2) radio, (3) handphone, dan (4) smartphone. Selanjutnya fungsi TIK dalam mendukung aktivitas pertanian di lokasi kajian yaitu Kabupaten Bantul ditunjukkan pada Tabel 3.

Petani di Kabupaten Bantul banyak memanfaatkan TV untuk mengakses informasi budidaya pertanian. Dari total 29 responden yang memiliki televisi, 34,48 \% kadang-kadang mengakses informasi mengenai teknik produksi pertanian. Sedangkan informasi pertanian yang sering diakses oleh petani melalui media televisi yaitu kebijakan $(24,14 \%)$ dan human interest (27,59\%).

Petani di Bantul menambahkan bahwa handphone dan smartphone berfungsi untuk teknis produksi dan pemasaran hasil pertanian. Handphone dan smartphone digunakan petani untuk menghubungi pihak-pihak yang berkaitan dengan usaha tani hortikultura, utamanya tengkulak yang akan membeli hasil usaha tani mereka.

Laptop cenderung memiliki fungsi yang minim dalam bidang pertanian dikarenakan responden yang memiliki laptop/PC tidak menggunakan untuk kepentingan pertanian melainkan untuk mencukupi kebutuhan peralatan belajar bagi putra/putri mereka yang masih menempuh sekolah. Selain itu minimnya fungsi laptop bagi petani di Bantul dikarenakan kemampuan petani untuk mengoperasionalkan piranti tersebut masih sangat terbatas. Beberapa responden memiliki DVD di rumah akan tetapi mereka menggunakan DVD untuk memperoleh hiburan dengan cara menyetel CD film, campursari, wayang, atau kegiatan kesenian yang lain sehingga hal ini menjadikan DVD tidak berfungsi dalam bidang pertanian.

\section{SIMPULAN}

Petani di Kabupaten Bantul mayoritas sudah memiliki media seperti televisi, radio, handphone, smartphone, laptop, dan VCD/ DVD. Media tersebut digunakan petani sebagai sarana memperoleh informasi, edukasi, dan hiburan. Pemanfaatan media elektronik dalam bidang pertanian menunjukkan sebagian besar petani menggunakan empat media yang mampu menyediakan informasi di bidang pertanian. Media tersebut yaitu (1) televisi, (2) radio, (3) handphone, dan (4) smartphone. Petani di Bantul menggunakan media tersebut untuk mendapatkan informasi terkait teknis produksi dan pemasaran,

\section{DAFTAR PUSTAKA}

\section{Artikel Jurnal}

Abidin, N.I., Rosnita, R. Yolida. 2015. Efektifitas Media Penyuluhan yang diberikan kepada Petani Karet di Desa Gunung BungsuKecamatan III, Kota Kampar. Jom Faperta Vol.2 No.2.

Bulu, Y. G., S. Sunaru, Herianto, S. Ageng. 2009. Pengaruh Modal Sosial dan Keterdedahan Informasi terhadap Tingkat Adopsi Inovasi Jagung di Kabupaten Lombok Timur, NTB. Jurnal Agroekonomi, Volume No. 1.

Elian, N., Lubis, D. P., Rangkuti, P.A. 2014. Penggunaan Internet dan Pemanfaatan Informasi Pertanian oleh Penyuluh Pertanian di Kabupaten Bogor Wilayah Barat. Jurnal Komunikasi Pembangunan, Juli 2014, Vol.12, No.2 (104-109). Institut Pertanian Bogor, Jawa Barat.

Harmoko dan E. Darmansyah, 2016. Akses Informasi Pertanian melalui Media Komunikasi pada Kelompok Tani di Kabupaten Sambas dan Kota Singkawang. 
Jurnal Komunikator Vol. 8 No. 1.

Mulyadi, M. 2012. Penelitian Kuantitatif dan Kualitatif serta Praktek Kombinasinya dalam Penelitian Sosial. Nadi Pustaka, Yogyakarta.

Nasir, M. 1999. Metode Penelitian. Ghalia Indonesia, Jakarta.

Subejo.2011. Babak Baru Penyuluhan Pertanian dan Pedesaan. Jurnal Ilmu-Ilmu Pertanian, Juli 2011, Vol. 7, Nomor 1 (61-70). Fakultas Pertanian UGM, Yogyakarta.

Subejo et.al,.2016. Akses dan Pemanfaatan TIK untuk Pertanian di Yogyakarta, Laporan Hibah Penelitian Fakultas Pertanian 2016 (tidak dipublikasikan) 